The University of Maine

\title{
DigitalCommons@UMaine
}

Earth Science Faculty Scholarship

Earth Sciences

9-1-2004

\section{Fracture and Back Stress Along the Byrd Glacier Flowband on the Ross Ice Shelf}

James P. Kenneally

Terence J. Hughes

University of Maine - Main, terry.hughes@maine.edu

Follow this and additional works at: https://digitalcommons.library.umaine.edu/ers_facpub

Part of the Earth Sciences Commons

\section{Repository Citation}

Kenneally, James P. and Hughes, Terence J., "Fracture and Back Stress Along the Byrd Glacier Flowband on the Ross Ice Shelf" (2004). Earth Science Faculty Scholarship. 36.

https://digitalcommons.library.umaine.edu/ers_facpub/36 


\title{
Fracture and back stress along the Byrd Glacier flowband on the Ross Ice Shelf
}

\author{
JAMES P. KENNEALLY ${ }^{1}$ and TERENCE J. HUGHES ${ }^{2}$ \\ ${ }^{1}$ Department of Physics, Climate Change Institute, University of Maine, Orono, ME 04469-5790, USA \\ 2 Department of Earth Sciences, Climate Change Institute, University of Maine, Orono, ME 04469-5790, USA
}

\begin{abstract}
East Antarctic ice discharged by Byrd Glacier continues as a flowband to the calving front of the Ross Ice Shelf. Flow across the grounding line changes from compressive to extensive as it leaves the fjord through the Transantarctic Mountains occupied by Byrd Glacier. Magnitudes of the longitudinal compressive stress that suppress opening of transverse tensile cracks are calculated for the flowband. As compressive back stresses diminish, initial depths and subsequent growth of these cracks, and their spacing, are calculated using theories of elastic and ductile fracture mechanics. Cracks are initially about one millimeter wide, with approximately $30 \mathrm{~m}$ depths and $20 \mathrm{~m}$ spacings for a back stress of $83 \mathrm{kPa}$ at a distance of $50 \mathrm{~km}$ beyond the fjord, where floating ice is $600 \mathrm{~m}$ thick. When these crevasses penetrate the whole ice thickness, they release tabular icebergs $20 \mathrm{~km}$ to $100 \mathrm{~km}$ wide, spaced parallel to the calving front of the Ross Ice Shelf.
\end{abstract}

Received 18 December 2003, accepted 23 April 2004

Key words: Antarctic, crevasse formation, glaciology

\section{Introduction}

Thomas (1973a, 1973b) introduced the concept of back stress to account for reduced spreading rates on the Brunt Ice Shelf in Coats Land, Antarctica. Back stress is defined qualitatively as stress induced by anything that resists forward motion of glacial ice, such as local pinning (grounding) points on an ice shelf, side shear on a glacier flowing through the confines of a fjord, and lateral drag from slower moving ice bordering a faster moving ice stream. A major cause of back stress is the buttressing effect an ice stream experiences as it flows into a large pinned and confined floating ice shelf, as is the case at many locations in Antarctica. Following Rist et al. (1996, 1999, 2002), this study uses fracture mechanics; first, to assess the magnitudes of the back stress along the floating portion of Byrd Glacier, shown in Fig.1 as it enters the Ross Ice Shelf, and second, to generate transverse fractures that lead to iceberg calving after the back stress diminishes.

\section{Stresses in floating ice}

Rist et al. (2002) did a quantitative analysis of back stress on the Ronne Ice Shelf using fracture mechanics. Field data were taken along a flowline on the floating ice, with ice cores recovered to determine density profiles and fracture toughness. Measurements of basal crevasse penetrations were made using radar profiling.

In order to employ a fracture mechanics analysis, the stresses in floating ice need to be determined. Longitudinal stress $\sigma_{x x}$ in the $x$ direction of ice flow can be written as:

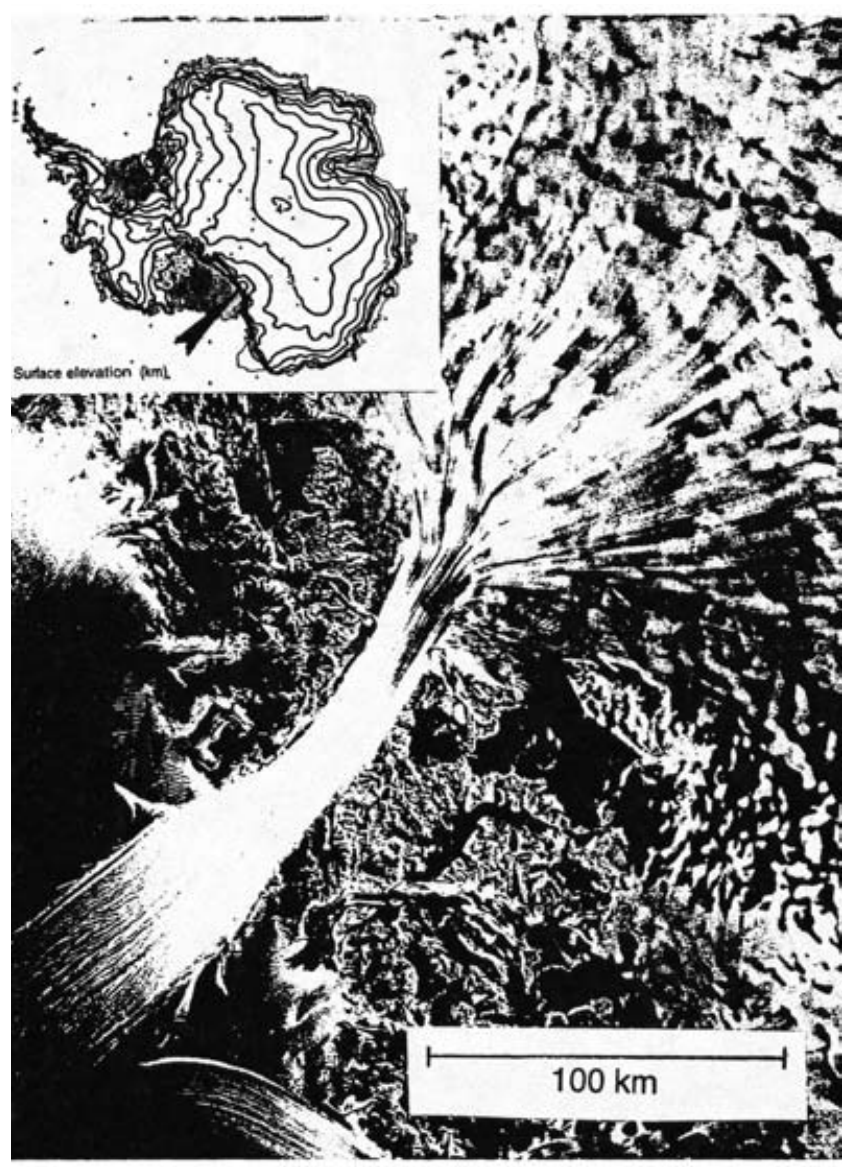

Fig. 1. Byrd Glacier and its flowband on the Ross Ice Shelf. Inset map shows location. From Jezek 1998. 


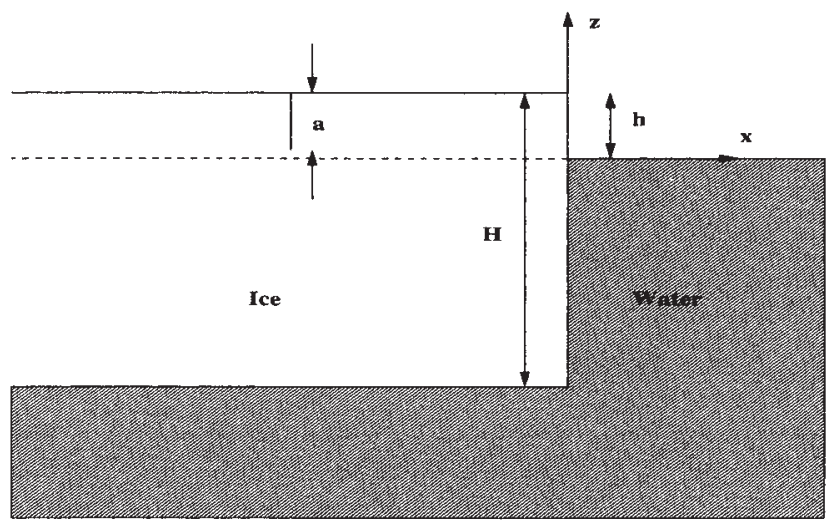

Fig. 2. Geometry for stress and fracture mechanics analysis.

$$
\sigma_{x x}=\sigma_{x x}^{\prime}+\frac{1}{3}\left(\sigma_{x x}+\sigma_{y y}+\sigma_{z z}\right)
$$

where $\sigma_{x x}^{\prime}$ is the longitudinal deviator stress, the $y$ direction is transverse to ice flow, and the $z$ direction is vertical. Incompressibility of ice, such that strain rates $\dot{\varepsilon}_{x x}+\dot{\varepsilon}_{y y}+\dot{\varepsilon}_{z z}=0$, requires that

$$
-\left(\sigma_{x x}^{\prime}+\sigma_{y y}^{\prime}\right)=\sigma_{z z}^{\prime}
$$

which allows the simplification that, averaged through the ice thickness, $\sigma_{x x}^{\prime}<<\sigma_{x x} \approx \sigma_{y y} \approx \sigma_{z z}$. Then Eq. (1) is approximated by:

$$
\sigma_{x x} \approx \sigma_{x x}^{\prime}+\sigma_{z z}
$$

where $\sigma_{z z}$ is the (negative) ice overburden pressure. The deviator stress is determined by the flow law of ice, as formulated by Thomas (1973a, 1973b):

$$
\sigma_{x x}^{\prime}=B(z)\left(\frac{\dot{\varepsilon}_{x x}}{\Theta}\right)^{1 / n}
$$

The term in parentheses is the contribution to the stress due to creep in the ice, while the variable B represents the ice hardness parameter, which is dependent on temperature, and therefore on depth $z$ through the ice, $n$ is a viscoplastic parameter, and $\Theta$ denotes the relative contribution to creep of shear and transverse deviator stresses. With these substitutions in Eq. (1), the stress in the horizontal direction of ice flow can be written as, for $n=3$ :

$$
\sigma_{x x}=B(z)\left(\frac{\dot{\varepsilon}_{x x}}{\Theta}\right)^{1 / 3}+\sigma_{z z}
$$

Weertman (1957) demonstrated that the term in parentheses is a positive constant; indicating that an unconfined ice shelf must lengthen due to creep. This constant term is obtained by balancing the force exerted by the ice column and that due to water pressure, i.e.

$$
\int_{b}^{s} \sigma_{x x} d z=\rho_{w} g \int_{b}^{0} z d z
$$

where $\rho_{w}$ is water density, $g$ is gravity acceleration, and $b$ and $s$ represent the base and surface of a floating ice shelf with $z$ vertical and positive upward in a coordinate system originating at sea level (Fig. 2). Substituting Eq. (5) into Eq. (6) and integrating the right hand side explicitly gives

$$
\int_{b}^{s}\left\{B(z)\left(\frac{\dot{\varepsilon}_{x x}}{\Theta}\right)^{1 / 3}+\sigma_{z z}\right\} d z=-\frac{1}{2} \rho_{w} g(H-h)^{2}
$$

for ice with total thickness $H$ and height $h$ above sea level. Since ice density $\rho_{i}$ is not constant with depth (Paterson 1994, Rist et al. 1996, 1999, 2002), ice overburden pressure is written as:

$$
\sigma_{z z}=-g \int_{z}^{s} \rho_{i}(z) d z
$$

and the height above sea level to which a floating ice column will rise is:

$$
h=H-\frac{1}{\rho_{w}} \int_{b}^{s} \rho_{i}(z) d z
$$

Substituting these values into Eq. (7) and solving for the constant term gives:

$$
\left(\frac{\dot{\varepsilon}_{x x}}{\Theta}\right)^{1 / 3}=\frac{1}{\int_{b}^{s} B(z) d z}\left\{g \int_{b}^{s} \int_{z}^{s} \rho_{i}(z) d z d z-\frac{g}{2 \rho_{w}}\left(\int_{b}^{s} \rho_{i}(z) d z\right)^{2}\right\}
$$

which can then be inserted into the original expression for the longitudinal stress in Eq. (5) to yield:

$$
\sigma_{x x}=\frac{B(z)}{\int_{b}^{s} B(z) d z}\left\{g \int_{b}^{s} \int_{z}^{s} \rho_{i}(z) d z d z-\frac{g}{2 \rho_{w}}\left(\int_{b}^{s} \rho_{i}(z) d z\right)^{2}\right\}-g \int_{z}^{s} \rho_{i}(z) d z
$$

This relation is an explicit formula for the longitudinal stress acting at any depth $z$ in floating ice. It is a non-linear relation determined by the dependence of density on depth and the dependence of $B$ on depth through the depth dependence of ice temperature. Both of these effects will be explicitly addressed later.

\section{Back stresses in floating ice}

Back stress can be included in the treatment by considering a longitudinal compressive back stress $\sigma_{c}$ of the form (Thomas \& MacAyeal 1982):

$$
\sigma_{c}=\frac{1}{H}\left(\frac{\dot{\varepsilon}_{c}}{\Theta}\right)^{1 / 3} \int_{b}^{s} B(z) d z
$$

This can then be subtracted from the longitudinal extending stress $\sigma_{\mathrm{xx}}$ in Eq. (3), as expressed in Eq. (11), to give a final depth dependent stress: 
$\sigma_{x x}=\frac{B(z)}{\int_{b}^{s} B(z) d z}\left\{g \int_{b}^{s} \int_{z}^{s} \rho_{i}(z) d z d z-\frac{g}{2 \rho_{w}}\left(\int_{b}^{s} \rho_{i}(z) d z\right)^{2}-\sigma_{c} H\right\}-g \int_{z}^{s} \rho_{i}(z) d z$

The inclusion of a back stress term allows for a general description of the stresses acting on the ice. In a fracture mechanics framework, the stress described by Eq. (13) lets one calculate the stresses acting on a crevasse within the ice. A non water-filled crevasse (most likely a surface crevasse in the presence of little or no surface melting) transverse to ice flow will be subject to a tensile stress given $\sigma$ by

$$
\sigma=\sigma_{x x}
$$

while a for water filled crevasse (on the surface or at the base), $\sigma$ will be given by

$$
\sigma=\sigma_{x x}+\sigma_{w}=\sigma_{x x}-\rho_{w} g z
$$

As written, $\sigma_{c}$ incorporates any effect that resists forward progress of the ice. It can assess magnitude but not causes of back stress. Assessing causes requires knowing the stress tensor in three dimensions, which is beyond the scope of this study.

\section{Fracture mechanics}

Following Rist et al. (2002), we employ a stress intensity factor (SIF) that is derived for a depth-dependent tensile stress $\sigma$. In order to do this, it is necessary to rewrite the depth dependent stress in terms of a polynomial of order $N$

$$
\sigma=\sum_{N} C_{N}\left(\frac{z}{H}\right)^{N}
$$

With the stress written in this form, the SIF for mode I cracks, those cracks that open in tension, is $K_{I}$ and is given by (Fett et al. 1990):

$$
K_{I}=\sqrt{a \pi} \sum_{N} C_{N} F_{N}\left(\frac{a}{H}\right)^{N}
$$

where $a$ is the crevasse depth and the $F_{N}$ are weighting functions determined to be

$$
F_{N}=\frac{\sqrt{2}}{\pi} N !\left[\frac{\Gamma(1 / 2)}{\Gamma(N+3 / 2)}+A_{l} \frac{\Gamma(3 / 2)}{\Gamma(N+5 / 2)}+A_{2} \frac{\Gamma(5 / 2)}{\Gamma(N+7 / 2)}+A_{3} \frac{\Gamma(7 / 2)}{\Gamma(N+9 / 2)}\right]
$$

with $\Gamma$ representing the standard gamma function.

This expression is determined by Fett et al. (1990) to be valid for $N \leq 5$ and normalized crevasse depths $\alpha=a / H \leq$ 0.9 . The $A_{i}$ are polynomials in $\alpha$ given by (correction in $A_{3}$ by Rist et al. 2002)

$$
\begin{array}{r}
A_{1}=\left(0.4523+1.1690 \alpha+8.5078 \alpha^{2}-13.6598 \alpha^{3}+4.4806 \alpha^{4}\right) /(1-\alpha)^{3 / 2} \\
A_{2}=\left(0.7017-2.2134 \alpha+2.7344 \alpha^{2}+4.6756 \alpha^{3}-6.0185 \alpha^{4}\right) /(1-\alpha)^{5 / 2}
\end{array}
$$

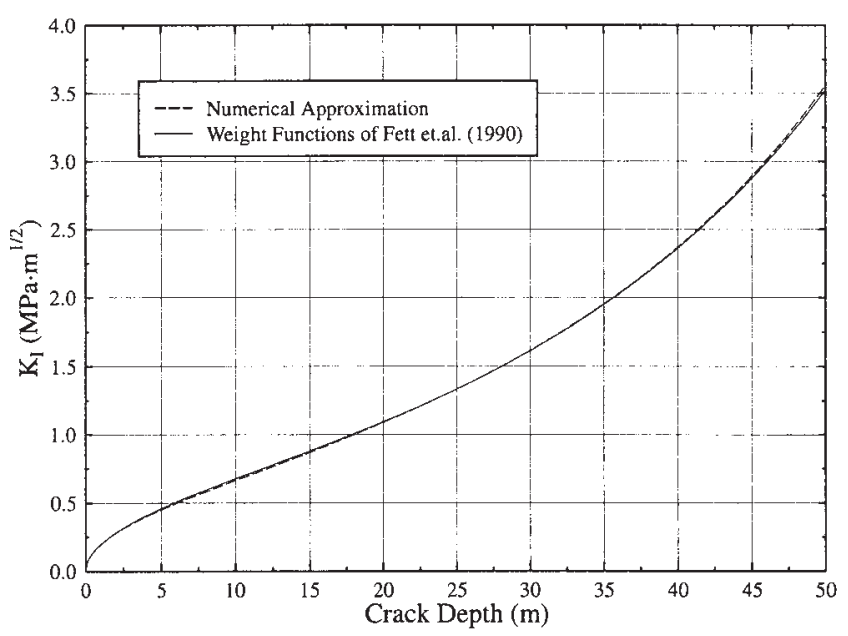

Fig. 3. The weight function given by Eq. (17) for an edge crack subjected to constant tensile stress. Tensile stress $\sigma=0.1 \mathrm{Mpa}$ and sample thickness $H=100 \mathrm{~m}$.

$$
A_{3}=\left(-0.3012+0.9970 \alpha-0.5156 \alpha^{2}-2.0149 \alpha^{3}+1.8843 \alpha^{4}\right) /(1-\alpha)^{5 / 2}
$$

The application of Eq. (17), plotted in Fig. 3, is simply a matter of fitting the stress given by Eq. (14) or Eq. (15) to a polynomial of order 5 and substituting the fitted coefficients. Stress $\sigma$ increases linearly with depth when ice density is constant, and is nearly linear when density varies according to Eq. (20).

\section{Back stresses on Byrd Glacier}

Thomas \& MacAyeal (1982) determined back stress on the Ross Ice Shelf, mainly for the western portion, and converted it into contours of a "retarding force." They measured strain rates at a number of field stations and numerically computed the retarding force necessary to rectify these strain rates with what an unopposed ice shelf of Weertman (1957) type would experience. Byrd Glacier dominates flow on the eastern portion of the ice shelf. As seen in Fig. 1, Byrd Glacier begins in the East Antarctic Ice Sheet and enters the Ross Ice Shelf in a fjord through the Transantarctic Mountains. The Ross Ice Shelf exerts a back stress on the floating lower portion of Byrd Glacier, causing compressive flow (Brecher 1982). Transverse crevasses do not form in this region. Extending and divergent flow becomes apparent after Byrd Glacier leaves the fjord and transverse crevasses appear. Crevasse depths depend on the longitudinal tensile stress, so if the depths are known, or assumed to be some value, the stress at any given point along the flowline can be deduced for specified ice properties.

Data necessary to apply Eq. (14) include knowledge of the relation of density with depth, the thickness of the floating portions of the ice and some idea of how the flow 


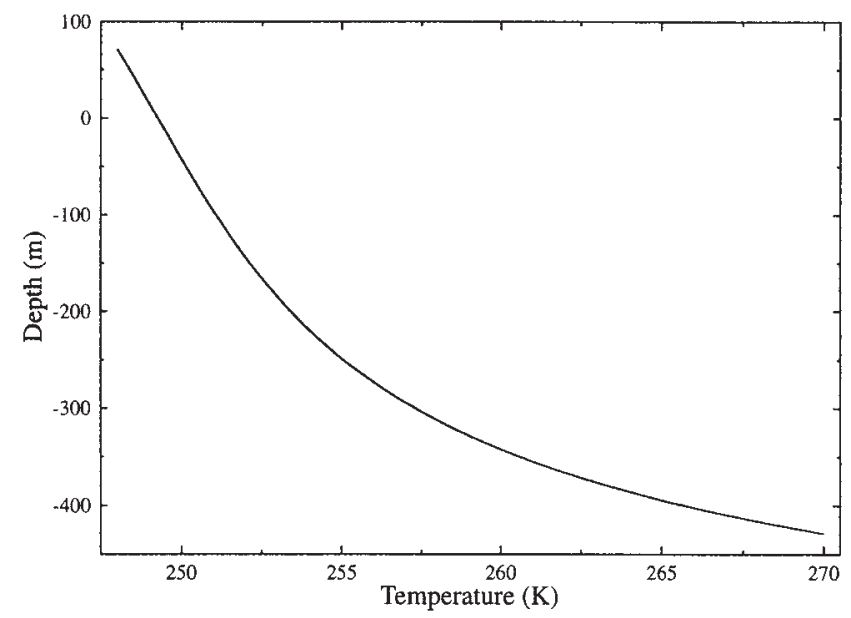

Fig. 4. The temperature profile as a function of depth for a glacier of thickness $500 \mathrm{~m}$ experiencing basal melting. Surface temperature is $-25^{\circ} \mathrm{C}$ and basal temperature is $-3^{\circ} \mathrm{C}$.

law parameter $B$ varies with depth. An exponential relation best describes the density as a function of depth (Paterson 1994):

$$
\rho_{i}(z)=\rho_{i}-\left(\rho_{i}-\rho_{s}\right) e^{-d / c}
$$

where $\rho_{i}$ is the density of pure ice, $\rho_{s}$ is density of snow and firn at the surface, $d$ is the depth below the surface and $c$ is a constant determined by experiment.

Ice hardness parameter $B$ is a function of temperature $T$, which varies with depth. The relation between $T$ and $z$ can be quite complicated so a numerical solution to $B$ is necessary, using the Arrhenius relation :

$$
B=B_{o} \exp \left(\frac{Q}{n R T(z)}\right)
$$

with $n$ the viscoplastic parameter in Eq. (4), $R$ the universal gas constant $\left(8.31 \mathrm{~J} \mathrm{~mol}^{-1} \mathrm{~K}\right)$ and $Q$ the activation energy for creep in ice, which is double-valued, depending on temperature. The values most commonly chosen are $Q=6 \mathrm{x}$ $10^{4} \mathrm{~J} \mathrm{~mol}^{-1}$ when $T<-10^{\circ} \mathrm{C}$ and $Q=13.9 \times 10^{4} \mathrm{~J} \mathrm{~mol}^{-1}$ when $T \geq-10^{\circ} \mathrm{C}$. The value of $B_{o}$ is chosen so that the function is continuous (but not necessarily differentiable) at the point where the transition in $Q$ takes place. Weis et al. (1999) modeled the temperature profile through a floating glacier as it enters an ice shelf. As Byrd Glacier enters the Ross Ice Shelf, the surface temperature is $-25^{\circ} \mathrm{C}$ (Thomas 1976 , Thomas et al. 1984). Basal temperatures for ice in contact with seawater, are near $-3^{\circ} \mathrm{C}$. The temperature profile for the high basal melting rates in the floating lower part of Byrd Glacier, as determined by Kenneally (2003), is shown in Fig. 4.

\section{Surface crevasses}

Zero unstable surface crevasse growth is considered in analysing the back stresses of Byrd Glacier. This case would result in the minimum back stress required for surface crevassing to remain within the stable regions of crack growth determined by Kenneally (2003), following Rist et al. (2002). The magnitude of the stress intensity factor for the crack would remain below the fracture toughness for all crack depths $a$.

Values of the back stress can be found by application of Eq. (14), represented by Eq. (16), and iterating through the back stress until surface crevasse depths found using Eq. (17) match what is observed or is posited to exist. The floating length of Byrd Glacier is undergoing compressive flow in the lower part of the fjord, so crevasse formation is completely retarded in this region. Floating ice thicknesses in the fjord are inferred using the non-linear density relation given by Eq. (20) and ice-surface elevation measurements by Brecher (1982). Thicknesses range from $800 \mathrm{~m}$ to $350 \mathrm{~m}$. Utilizing Eq. (13) for various ice thicknesses $H$ results in longitudinal stresses present in the floating ice. There are

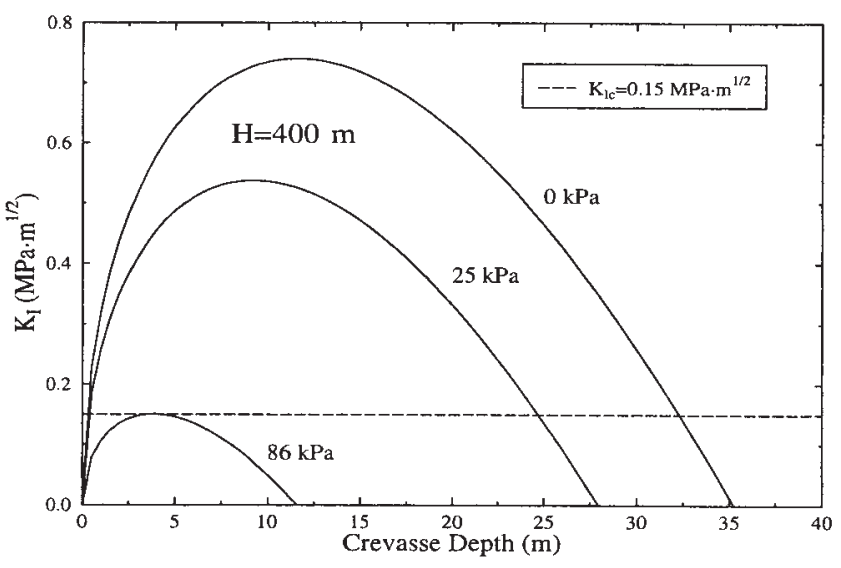

(a)

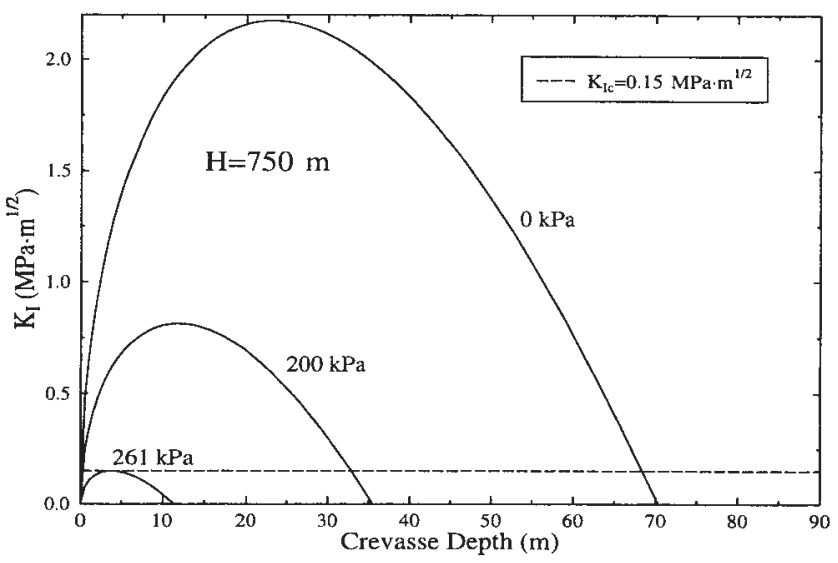

(b)

Fig. 5. Stress intensity factor as a function of crevasse depth for a range of back stresses. 


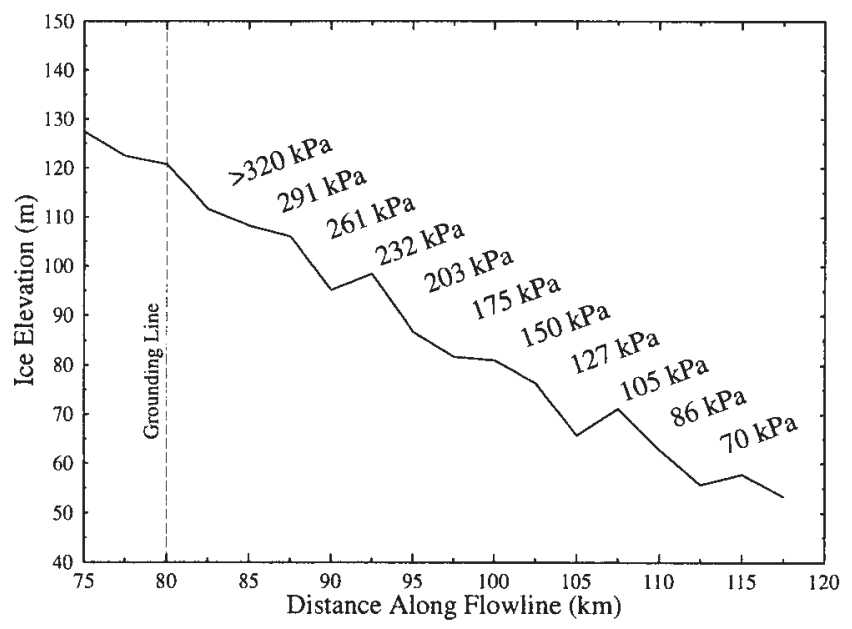

Fig. 6. Back stresses at locations along the floating portion of Byrd Glacier is such that no crevasse growth can occur.

three unique components to stress $\sigma_{\mathrm{xx}}$; the tensile deviator stress $\sigma_{\mathrm{xx}}$ due to creep, the ice overburden stress $\sigma_{z z}$, and the compressive back stress $\sigma_{c}$. The mode I stress intensity factor for tensile cracks is found by recalling that the net stress intensity factor is the sum of the individual stress intensity factors contributing to the stress

$$
K_{\text {total }}=\sum_{i} K_{i}=K_{\text {tensile }}+K_{\text {overhurden }}+K_{\text {back }}
$$

where each $K_{i}$ is found using Eq. (17), subscript I for each $K$ is assumed to be understood, thus is omitted for clarity.

Calculated stress intensity factors for ice of thicknesses $H=400 \mathrm{~m}$ and $H=750 \mathrm{~m}$ are shown in Fig. 5. In each figure, the dashed line represents the fracture toughness of ice $K_{I c}$ determined by Rist et al. (2002) to be $0.15 \mathrm{MPa} \mathrm{m}^{1 / 2}$. In each case, a stress intensity factor (SIF) for a given back stress is shown that is tangent to the fracture toughness. The value of $\sigma_{c}$ that results in this tangent SIF is the minimum back stress necessary to retard unstable crack growth

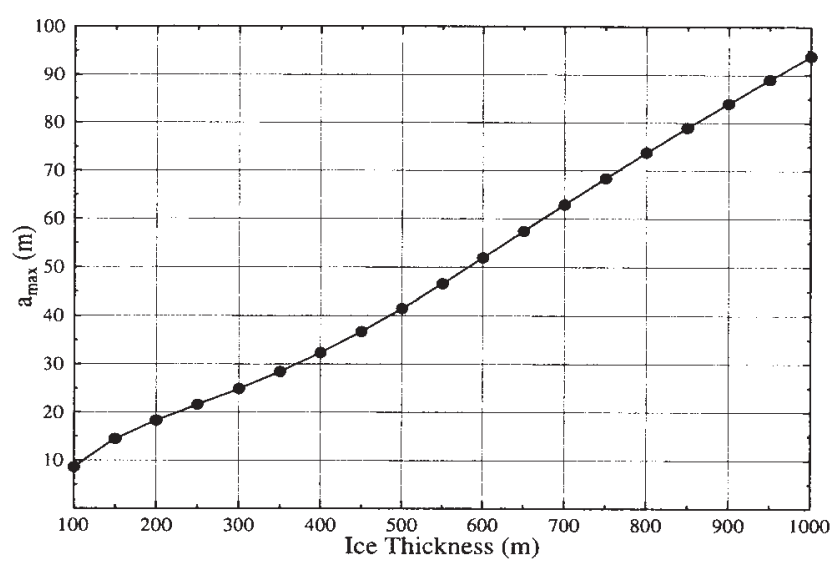

Fig. 7. Maximum crevasse penetration as a function of ice thickness for zero back stress.

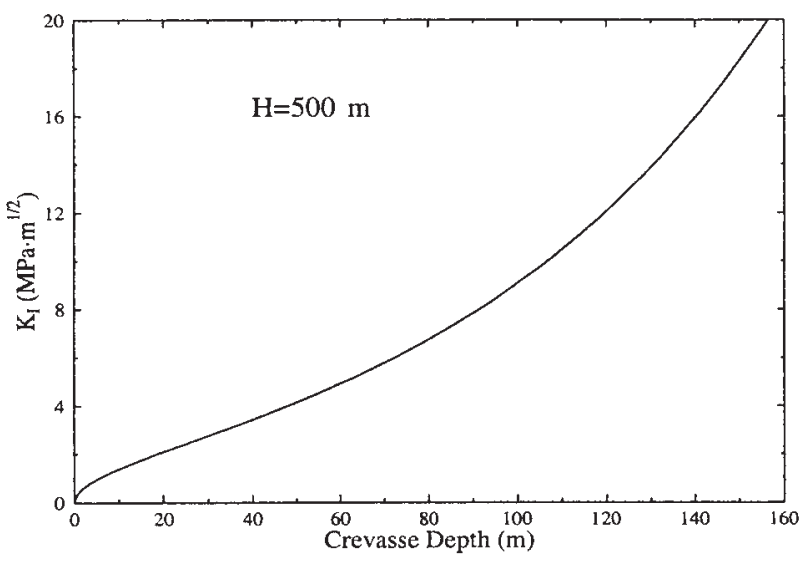

Fig. 8. Stress intensity factor for a basal crevasse as a function of penetration depth, measured from the base of the ice, for $\sigma_{\mathrm{c}}=0$. Overburden stress on its own is insufficient to pinch shut a crack once growth is initiated, because $\mathrm{K}_{1}$ increases with crevasse depth without bound.

entirely. A map of the back stresses necessary for this condition to hold is shown in Fig. 6.

This example demonstrates the procedure for determining the back stresses along a flowline in floating ice. It can be applied to any field data that are collected, so when a crevasse is measured to be at some depth $a_{\text {observed }}$, the procedure can be carried out by iterating the back stress until the stress intensity factor intercepts the fracture toughness curve, thereby matching the observation. Back stresses found here are consistent with those in previous work (Rist et al. 2002, Thomas \& MacAyeal 1982). These iterations begin with zero back stress, see Fig. 7 .

\section{Basal crevasses}

This analysis can also be applied to basal crevasses by using Eq. (15) and proceeding in the same way. A basal crevasse is the most obvious example of a water-filled crevasse, since sea-water will rise into the crevasse as it penetrates the ice. Water-filled crevasses are inherently unstable due to the difference in the densities of water and ice. The ice overburden pressure is not sufficient to close a crevasse that is filled with the denser water, as illustrated in Fig. 8 for zero back stress. This instability leads to the observation that floating ice in a location where there is little or no back stress cannot exist when water filled crevasses are prevalent. The recent breakup of the Larsen B Ice Shelf on the Antarctic Peninsula is such an example (MacAyeal et al. 2003). Local warming resulted in extensive meltwater production, causing surface crevasses to fill with water. Back stresses that may have been present, including the pressure of pack ice in the Weddell Sea, where unable to prevent catastrophic breakup of the ice shelf. 

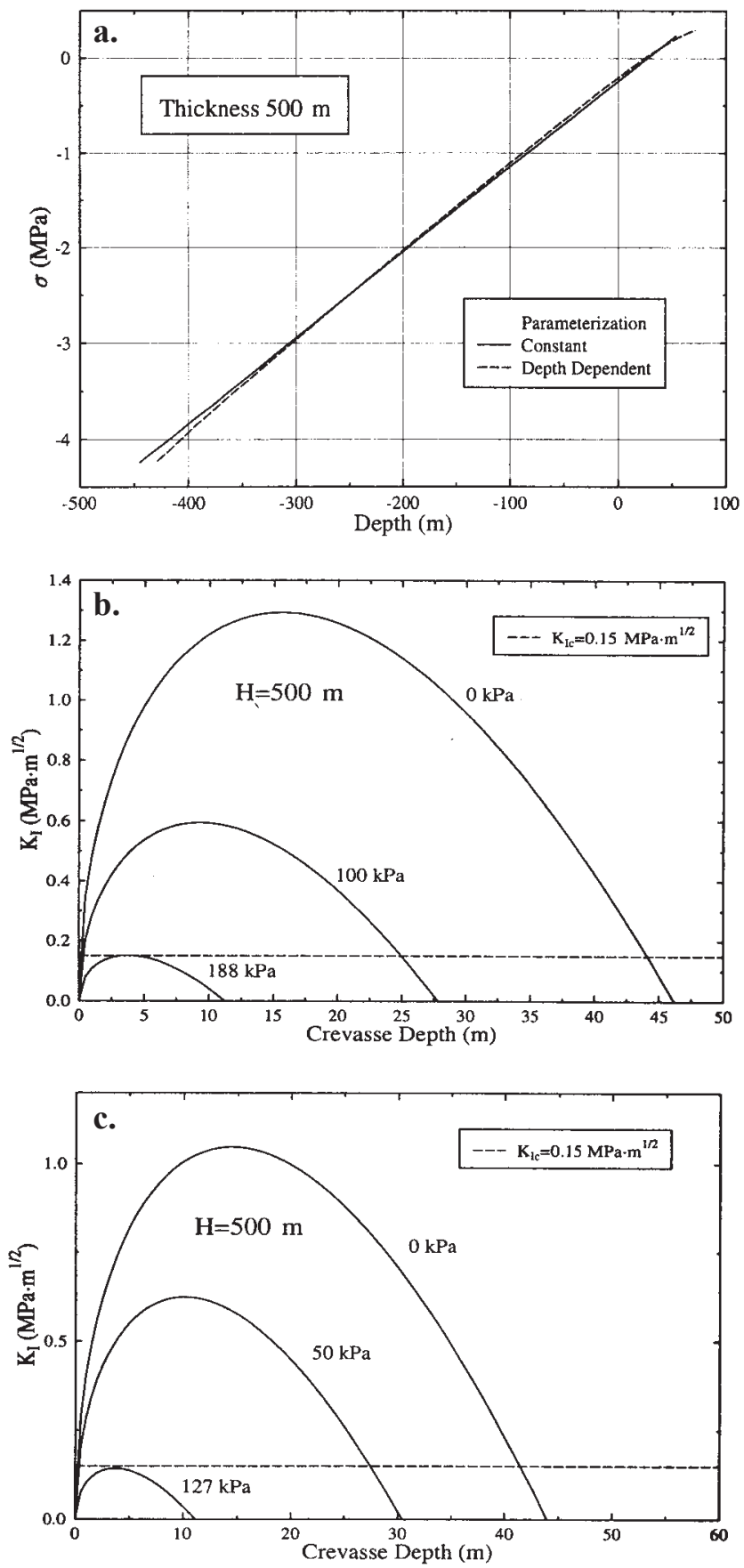

Fig. 9. a. Comparison of the stresses in floating ice of thickness $500 \mathrm{~m}$ depth dependent and constant ice density. Stress intensity factors are shown with the critical back stress necessary to retard fracture for $\mathbf{b}$. the constant density case, and $\mathbf{c}$. the depth dependent density case.

\section{Constant ice properties with depth}

Ice hardness $B$ depends on the variation of temperature $T(z)$ with depth through the ice, and ice density $\rho_{i}$ has a depthdependence given by Eq. (20). The situation where $B$ and $\rho_{i}$ are constant with depth is shown here for comparison. In this case Eqs (11) \& (13) simplify to

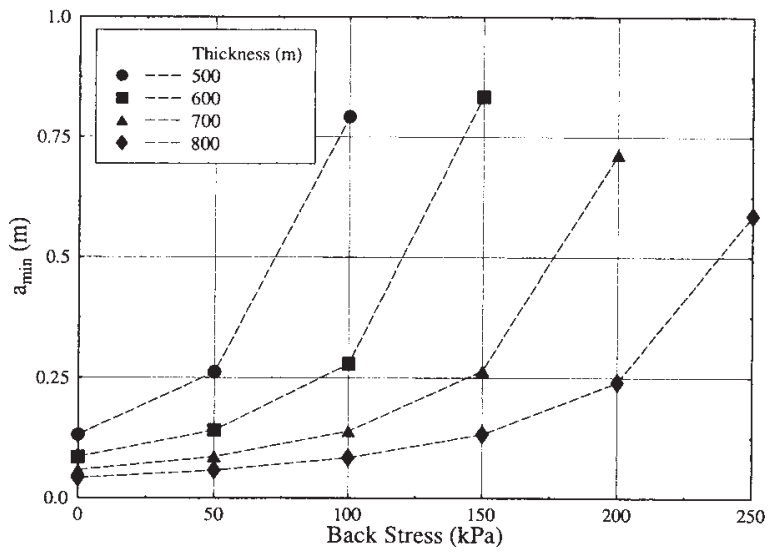

Fig. 10. Minimum crack depths required to achieve unstable crack growth for a range of ice thicknesses.

$$
\sigma_{x x}=\frac{1}{2} \rho_{i} g H\left(1-\frac{\rho_{i}}{\rho_{w}}\right)-\rho_{i} g z
$$

and

$$
\sigma_{x x}=\frac{1}{2} \rho_{i} g H\left(1-\frac{\rho_{i}}{\rho_{w}}\right)-\sigma_{c}-\rho_{i} g z
$$

Results using $\rho_{i}=917 \mathrm{~kg} \mathrm{~m}^{-3}, \rho_{w}=1002 \mathrm{~kg} \mathrm{~m}^{-3}$, and $H=500 \mathrm{~m}$ are shown in Fig. 9, which shows that the critical back stress is higher when density and temperature are constant. Thus, greater gravitational forcing induces greater resistance. One notable difference between the stresses in Fig. 9a is the flotation height of the ice. The constant density solution results in a flotation height $h \approx 54 \mathrm{~m}$, while $h \approx 71$ $\mathrm{m}$ for the parameterized density. The non-linearity of the true stress is also clear in this picture and this no doubt influences the stress intensity factor.

\section{Crevasse initiation}

How a new crevasse forms in glacial ice is unclear, but some possibilities may include the effects of bed conditions for grounded ice or tidal flexure at a grounding line for floating ice (Lingle et al. 1981). In particular, crevasses formed at grounding lines can have their growth stifled if, as in the case of Byrd Glacier, flow is compressive for some downstream distance and then crevasse growth is reactivated at a farther distance when flow becomes extensive.

The direction of crack propagation has been discussed by Sih (1991), using the strain energy density concept. The first hypothesis of this concept states crack initiation will start in a radial direction along which the strain energy density is a minimum. The strain energy density is given by

$$
S=a_{11} k_{1}^{2}+2 a_{12} k_{1} k_{2}+a_{22} k_{2}^{2}+a_{33} k_{3}^{2}
$$


where the $a_{i j}$ are functions of the angle $\theta$ from the crack tip to the infinitesimal volume element being analysed, Poisson's ratio is $v$ and the shear modulus of elasticity is $\mu$. The $k_{i}$ represent normalized stress intensity factors for mode I, II, and III cracks. In the case of mode I fracture, Eq. (25) takes the form

$$
S=\frac{\sigma^{2} a}{16 \mu}[(3-4 v-\cos \theta)(1+\cos \theta)]
$$

where $k_{i}=\sigma a^{1 / 2}$ and $k_{2}=k_{3}=0$. In order to find the minimum of Eq. (26), the derivative with respect to $\theta$ is taken and set equal to zero. This yields solutions $\theta=0$ and $\cos \theta=1-2 \mathrm{v}$. Inserting these values into the second derivative of $S$ determines whether the value is a maximum or minimum. Using this criteria, $\theta=0$ is found to be a minimum. The hypothesis requires that cracks grow in a direction along the axis of the initial crack, and perpendicular to the applied stress.

An examination of the SIF functions is necessary to determine the actual size of a "starter" crevasse. Figure 5 shows that the general shape of the SIF is convex, so the SIF curve will intercept the fracture toughness line at two locations. The point where the SIF intercepts fracture toughness $K_{I c}$ for the second time has already been discussed and is used to calculate the maximum depth to which a crevasse will penetrate. Points along the SIF curve that exceed the toughness are unstable, so the crack grows from the first to the second intersection almost instantly. Cracks that are very shallow will not propagate in this unstable fashion unless they achieve a depth such that the SIF becomes greater than the fracture toughness, which is located graphically at the point where the SIF curve first intersects the fracture toughness line. The minimum crevasse depths required for unstable growth are shown in Fig. 10. The deepest initial crevasse that can form will be the one that results when the back stress $\sigma_{c}$ is just below its critical value $\sigma_{c r}$. This crevasse depth, symbolized by $a_{0}$, will be the maximum initial crevasse depth that can form, since values of the back stress less than $\sigma_{c r}$ will result in more shallow starter crevasses (see Fig. 5). Explicitly, $a_{0}$ can be found by solving

$$
K\left(a_{0} ; H, \sigma_{c}\right)=K_{I c}
$$

for some ice thickness $H$ and its corresponding critical back stress $\sigma_{c r}$, as calculated in the Surface Crevasses section. The range of starter crevasse depths $a_{\min }$ for $\sigma_{c}<\sigma_{c r}$ will then be $0 \leq a_{\min } \leq a_{0}$.

\section{Crevasse propagation}

When ice becomes afloat, the longitudinal strain rate induced by stresses can be written for linear ice flow with constant ice temperature and density as (Thomas 1973a, 1973b):

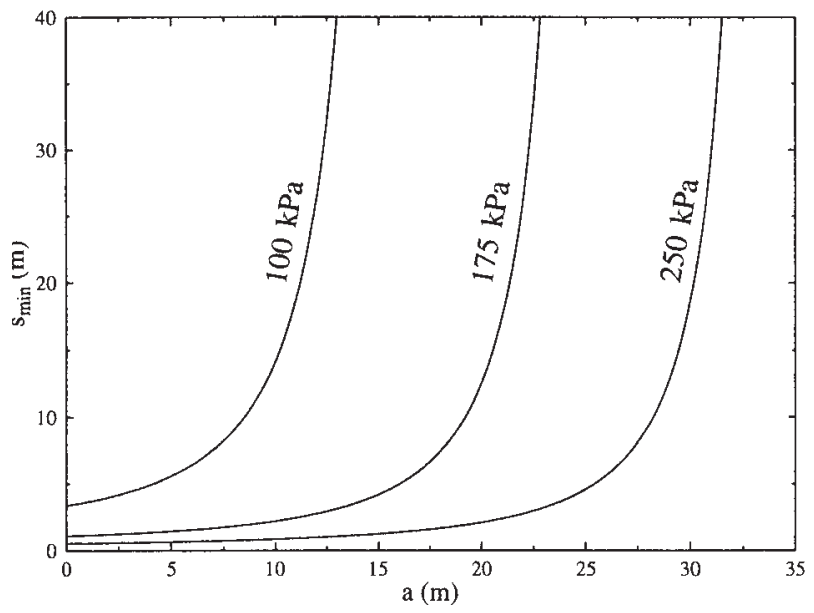

Fig. 11. Minimum spacing necessary to allow crevasse growth according to Eq. (33). Spacings for three values of the longitudinal deviator stress $\sigma_{\mathrm{xx}}^{\prime}$ are shown.

$$
\dot{\varepsilon}_{x x}=\left[\frac{\rho_{i} g H}{4 B}\left(1-\frac{\rho_{i}}{\rho_{w}}\right)-\frac{\sigma_{c}}{2 B}\right]^{3}
$$

where $H$ is the total thickness of the ice, $B$ is the ice hardness parameter and $\sigma_{c}$ is the compressive back stress in the ice. Contained within this expression is the overall longitudinal deviator stress for linear ice flow:

$$
\sigma_{x x}^{\prime}=\frac{1}{4} \rho_{i} g H\left(1-\frac{\rho_{i}}{\rho_{w}}\right)-\frac{1}{2} \sigma_{c}
$$

for which $2 \sigma_{\mathrm{xx}}=\sigma_{\mathrm{xx}}-\sigma_{\mathrm{zz}}$.

Assume that the ratio of crevasse width $w$ to spacing $s$ is constant as the crevasse migrates downstream, i.e.

$$
\frac{w_{i}}{s_{i}}=\frac{w_{f}}{s_{f}}
$$

where subscript $i$ and $f$ refer to initial and final conditions. The initial width $w_{i}$ of newly formed crevasses is determined by dislocation theory applied to a ductile zone at the crevasse tip (Weertman 1996, p. 377). The initial spacing $s_{i}$ of newly formed crevasses was given by Weertman (1977):

$$
S_{\min }=\left(\frac{K_{c}}{\sigma_{x x}}\right)^{2}
$$

where $s_{\text {min }}$ denotes the minimum spacing required to have any crevasse growth in ice with fracture toughness $K_{c}$. This equation is a simplification of a relation describing crevasse spacing as a function of crevasse depth $a$ (Weertman 1977, p. 41):

$$
a=\frac{1}{\rho_{i}(z) g}\left[\sigma_{x x}^{\prime}-K_{c}\left(\frac{2}{\pi s}\right)^{1 / 2}\left(\frac{2 \pi}{\pi+1}\right)\right]
$$

Solving Eq. (32) for $s$ as a function of crevasse depth $a$ 
Table I. Ross Ice Shelf data. Ice thickness is taken from Bentley \& Jezek (1981) while retarding force and ice hardness parameter are taken from Thomas \& MacAyeal (1982).

\begin{tabular}{ccccc}
\hline $\begin{array}{c}\text { Distance from } \\
\text { fjord entrance } \\
(\mathrm{km})\end{array}$ & $\begin{array}{c}\text { Ice } \\
\text { thickness } \\
(\mathrm{m})\end{array}$ & $\begin{array}{c}\text { Retarding } \\
\text { force } \\
(\mathrm{MN} / \mathrm{m})\end{array}$ & $\begin{array}{c}\text { Calculated } \\
\text { back stress } \\
(\mathrm{k} \mathrm{Pa})\end{array}$ & $\begin{array}{c}\text { Ice hardness } \\
\text { parameter } \\
\left(10^{7} \mathrm{~Pa} \mathrm{~s}^{1 / 3}\right)\end{array}$ \\
\hline 50 & 600 & 560 & 83 & 15 \\
175 & 400 & 45 & 112 & 17 \\
350 & 300 & 10 & 33 & 19 \\
\hline
\end{tabular}

results in

$$
s=\frac{8 \pi}{(\pi+1)^{2}}\left(\frac{K_{c}}{\sigma_{x x}^{\prime}-a \rho_{i}(a) g}\right)^{2} \approx \frac{3}{2}\left(\frac{K_{c}}{\sigma_{x x}^{\prime}-a \rho_{i}(a) g}\right)^{2}
$$

where the density is now also a function of crevasse depth. Results for Eq. (33) as a function of crevasse depth can be seen in Fig. 11 for a range of values of longitudinal deviator stress $\sigma_{x x}^{\prime}$. In order to get final spacing $s_{f}$ the final width of the crevasse is needed. This can be found by calculating the strain rate in the ice using Eq. (28) and applying it appropriately to the initial crevasse width.

Strain rates on the Ross Ice Shelf can be calculated from data presented in Table I obtained by Thomas \& MacAyeal (1982) and Bentley \& Jezek (1981) for the flowband that originates at Byrd Glacier and travels towards the calving ice front. Using these data, strain rates in Fig. 12 were calculated at three locations along the flowband using Eq. (28). The largest extending strain rate occurs at the location nearest the fjord entrance, but $50 \mathrm{~km}$ downstream, and is $\dot{\varepsilon}=1.1+10^{-2} \mathrm{yr}^{-1}$. It takes ice exiting the fjord approximately 67 years to reach this point, for an average velocity of $750 \mathrm{~m} \mathrm{yr}^{-1}$. The strain rate can be converted to a

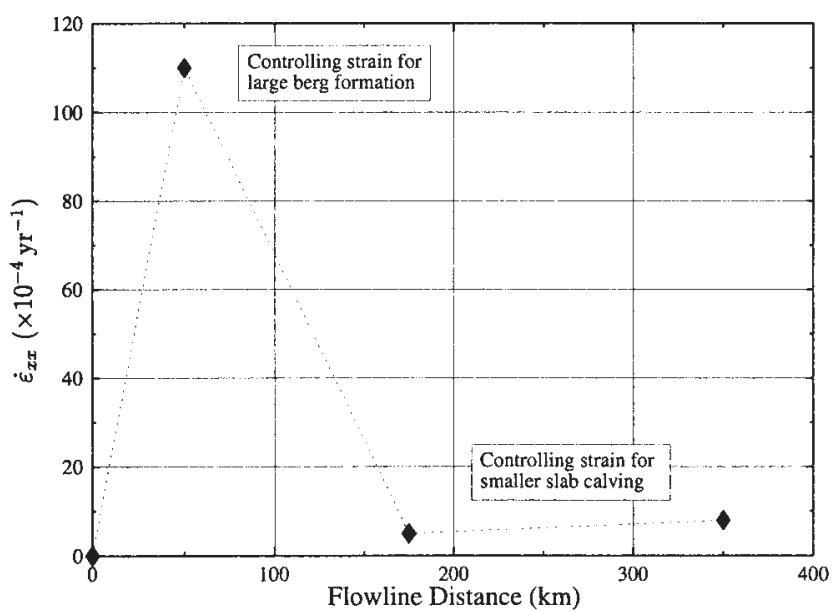

Fig. 12. Calculated strain rates along the Byrd Glacier flowband onto the Ross Ice Shelf. Larger strain rates farther upstream may be the controlling mechanism for large scale iceberg formation, while smaller strains nearer the calving front may control the smaller and more frequent calving events.

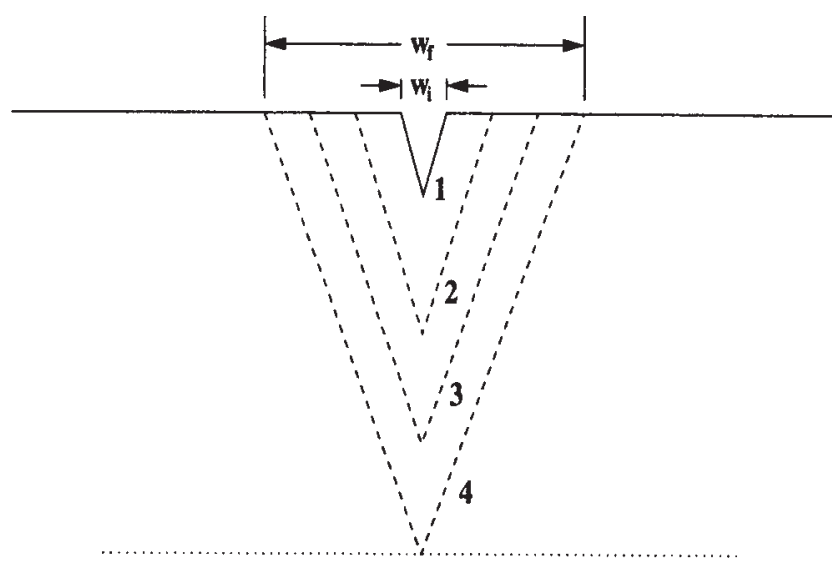

Fig. 13. Illustration of crevasse widening as crevasse depth increases. The depth grows from the situation labelled by 1 to that in 4, which represents its maximum penetration depth as determined by fracture mechanics. The crevasse widens from $w_{i}$ to $w_{f}$ during the time it is penetrating into the ice.

strain by the simple relation

$$
\varepsilon_{x x}=\dot{\varepsilon}_{x x} \Delta t
$$

for $\Delta t=67$ years. When this strain is applied to an initial crevasse width of $1 \mathrm{~mm}$ the final width at the ice margin is at most only twice the initial width, since strains farther downstream are very small and contribute negligibly to widening. From Eq. (30), this results in final crevasse spacings that are only double the initial spacing, at most, which itself is on the order of tens of metres. This exercise shows that extending flow does not determine crevasse spacing.

An alternative mechanism relates crevasse width $w$ to depth $a$ by a relation

$$
w=f(a) a
$$

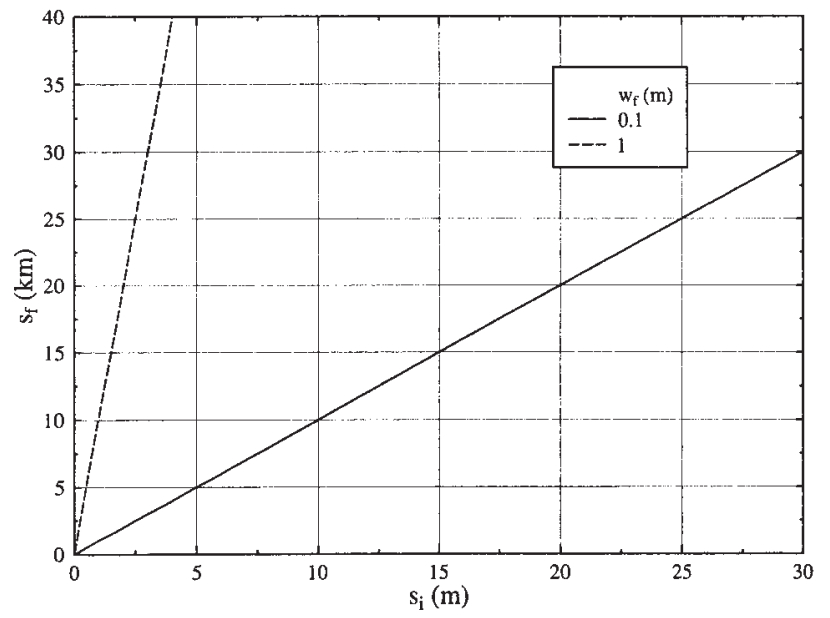

Fig. 14. Final crevasse spacing under the current analysis. Two values for final crevasse width $w_{f}$ result in spacings on the order of the largest tabular icebergs. 
where $f(a)$ is an enhancement factor that is dependent on depth. This mechanism is illustrated in Fig. 13. Consider data in Table I for the $50 \mathrm{~km}$ location. This is where the largest extending strains occur; thus it can be inferred that crevasses can form at this point and may be the controlling factors in large iceberg formation. The measured back stress is $83 \mathrm{kPa}$ and the ice is $600 \mathrm{~m}$ thick. The Surface Crevasse section showed how crevasse penetration depth could be determined for various back stresses. In this case, $\sigma_{c}=83$ $\mathrm{kPa}$ allows a maximum crevasse depth of $\mathrm{a}_{\max } \approx 30 \mathrm{~m}$. If this value of $\mathrm{a}_{\max }$ is inserted into Eq. (33) with density given by Eq. (20), then initial spacing necessary to allow for crack growth is found to be $s_{i} \approx 20 \mathrm{~m}$. Equation (30) can now be combined with Eq. (34), using observed initial crevasse widths (Swithinbank 1999) so that final spacing is:

$$
s_{f}=s_{i} \frac{w_{f}}{w_{i}}=s_{i} \frac{f(a) a_{f}}{f(a) a_{i}}=s_{i} \frac{a_{f}}{a_{i}}
$$

Equation (35) gives $s_{f} s_{i}$ ratios between $10^{3}$ and $10^{4}$. This gives values of the final spacing that are certainly large enough to result in the full size range of tabular icebergs. The relation in Eq. (35) is plotted in Fig. 14 for two values at the lower end of observed final widths $w_{f}$. Initial width in each case is taken to be only $1 \mathrm{~mm}$, as observed by Swithinbank (1999, p. 96) and calculated using dislocation theory for a ductile crack tip (Weertman 1996, p. 377). The size and shape of the ductile zone is calculated from plasticity theory, see Appendix A.

\section{Conclusions}

Any discussion that attempts to explicitly determine a relation describing calving processes from a theoretical standpoint is a precarious venture. This is especially true for calving from ice shelves, given their complex boundaries and flow regimes (Weis et al. 1999). The flowband of Byrd Glacier on the Ross Ice Shelf is close to an idealized flowband and considerable data are available to make worthwhile a first-order investigation of the relationship between longitudinal gravitational extension and side shear that resists extension of the flowband. A standard linear elastic analysis of cracking is combined with ductile deformation at the crack tip to produce transverse crevasses that allow tabular icebergs to calve at spacings of $20 \mathrm{~km}$ to $200 \mathrm{~km}$. This encompasses the largest Antarctic icebergs.

\section{Acknowledgements}

We thank the US National Science Foundation, Office of Polar Programs, for funding this research and Beverly Hughes for preparing the manuscript and figures for submission and publication. The first author, J.P. Kenneally, is now in Malawi as a US Peace Corps volunteer. We especially thank Martin Rist, Christopher Doake, and Michiel van den Broeke for their careful review and editing of our manuscript.

\section{References}

Bentley, C.R. \& JeZeK, K.C. 1981. RISS, RISP and RIGGS: post-IGY glaciological investigations of the Ross Ice Shelf in the US programme. Journal of the Royal Society of New Zealand, 11, 355-372.

BRECHER, H.H. 1982. Photographic determination of surface velocities and elevations on Byrd Glacier. Antarctic Journal of the United States, 17(5), 79-81.

FetT, T., MunZ, D. \& Neumann, J. 1990. Local stress intensity factors for surface cracks in plates under power-shaped stress. Engineering Fracture and Mechanic,s 36, 647-651.

JEZEK, K.C., ed. 1998. Early results from the first RADARSAT-1 Antarctic Mapping Mission. Byrd Polar Research Center Technical Report 98-02. Byrd Polar Research Center, The Ohio State University, 22 pp.

KenNeally, J.P. 2003. Crevassing and calving of glacial ice. $\mathrm{PhD}$ thesis, University of Maine, Orono, $133 \mathrm{pp}$. [Unpublished].

Lingle, C.S., Hughes, T. \& Kollmeyer, R.C. 1981. Tidal flexure of Jakobshavns Glacier, West Greenland. Journal of Geophysical Research, 86(B5), 3960-3968.

MacAyeal, D.R., Scambos, T.A., Hulbe, C.L. \& Fahnestock, M.A. 2003. Catastrophic ice-shelf break-up by an ice-shelf fragment capsize mechanism. Journal of Glaciology, 49, 22-36.

Paterson, W.S.B. 1994. The physics of glaciers. Oxford: Pergamon Publishing, 480 pp.

Rist, M.A., Sammonds, P.R., Murrell, S.A.F., Meredith, P.G., Doake, C.S.M., Oerter, H. \& MATSUKI, K. 1999. Experimental and theoretical fracture mechanics applied to Antarctic ice fracture and surface crevassing. Journal of Geophysical Research, 104, 2973-2987.

Rist, M.A., SAmmonds, P.R., Murrell, S.A.F., Meredith, P.G., Oerter, H. \& DOAKE, C.S.M. 1996. Experimental fracture and mechanical properties of Antarctic ice: preliminary results. Annals of Glaciology, 23, 85-102.

Rist, M.A., SAmmonds, P.R., Oerter, H. \& Doake, C.S.M. 2002. Fracture of Antarctic shelf ice. Journal of Geophysical Research, 107, 1-13.

SiH, G.C. 1991. Mechanics of fracture initiation and propagation: surface and volume energy density applied as failure criterion. Dordrecht: Kluwer Academic Publishers, 428 pp.

Swithinbank, C. 1999. Foothold on Antarctica: The First International Expedition (1949-1952) through the eyes of its youngest member. Lewes: The Book Guild Ltd, 260 pp.

Thomas, R.H. 1973a. The creep of ice shelves: theory. Journal of Glaciology, 12, 45-53.

ThOMAs, R.H. 1973b. The creep of ice shelves: interpretation of observed behaviour. Journal of Glaciology, 12, 55-70.

THOMAs, R.H. 1976. The distribution of $10 \mathrm{~m}$ temperatures on the Ross Ice Shelf. Journal of Glaciology, 16, 111-117.

Thomas, R.H. \& MAcAyeal, D.R. 1982. Derived characteristics of the Ross Ice Shelf. Journal of Glaciology, 28, 397-412.

Thomas, R.H., MacAyeal, D.R., EILers, D.H. \& Gaylord, D.R. 1984. Glaciological studies of the Ross Ice Shelf, 1973-1978. Antarctic Research Series, 42, 21-53.

Weertman, J. 1957. Deformation of floating ice shelves. Journal of Glaciology, 3, 38-42.

Weertman, J. 1977. Penetration depth of closely spaced water-free crevasses. Journal of Glaciology, 18, 37-46.

WeERTMan, J. 1996. Dislocation based fracture mechanics. Hackensack, NJ: World Scientific Publishing, 524 pp.

Weis, M., Greve, R. \& Hutter, K. 1999. Theory of shallow ice shelves. Continuum Mechanics and Thermodynamics, 11, 15-50. 


\section{Appendix A: Size of the plastic zone at a crack tip}

A determination of the size of the plastic zone surrounding a ductile crack tip begins with specifying a yield criterion. The von Mises yield criterion states that, for a specimen under uniaxial tension, yielding will occur when the yield stress $\sigma_{Y}$ is given by the square root of the second invariant of deviator stresses.

$$
\sigma_{Y}=\frac{1}{\sqrt{2}}\left[\left(\sigma_{1}-\sigma_{2}\right)^{2}+\left(\sigma_{2}-\sigma_{3}\right)^{2}+\left(\sigma_{1}-\sigma_{3}\right)^{2}\right]^{1 / 2}
$$

where $\sigma_{1}, \sigma_{2}$, and $\sigma_{3}$, are the principal stresses of the system. They can be related to the stress intensity factor $K_{l}$ for a tensile crack. Since the systems under consideration here are very thick, any-out-of plane deformation will be assumed small compared to overall thickness and plane strain can be assumed (Weis et al. 1999). The principal stresses, with $\sigma_{3}=v\left(\sigma_{1}+\sigma_{2}\right)$ using Poisson's ration $v$ for plane strain, then become infinite for $r=0$ at the crack tip:

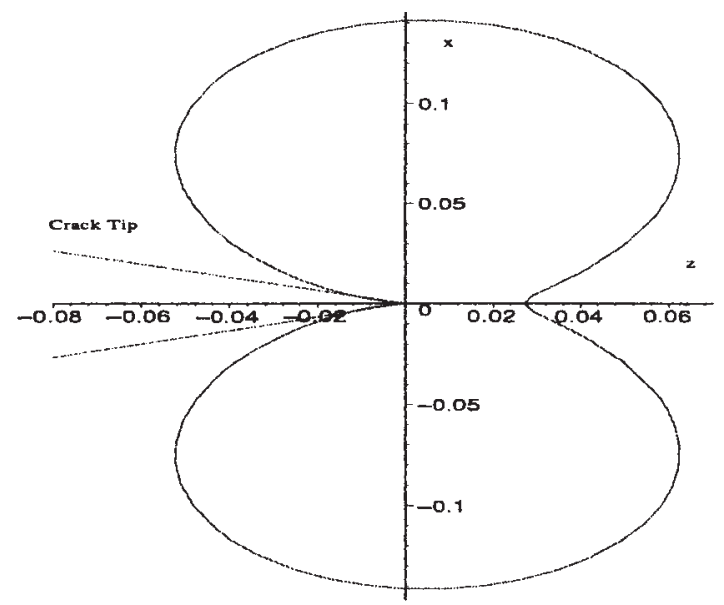

Fig. A1. Polar plot of the plastic zone $r_{p}$, measured in metres, for plane strain conditions.

$$
\begin{gathered}
\sigma_{1}=\frac{K_{1}}{\sqrt{2 \pi r}} \cos \frac{\theta}{2}\left(1+\sin \frac{\theta}{2}\right) \\
\sigma_{2}=\frac{K_{1}}{\sqrt{2 \pi r}} \cos \frac{\theta}{2}\left(1-\sin \frac{\theta}{2}\right) \\
\sigma_{3}=2 v \frac{K_{1}}{\sqrt{2 \pi r}} \cos \frac{\theta}{2}
\end{gathered}
$$

These results can be substituted into Eq. (A1) and the extent $r_{P}$ of the plastic zone, within which $\sigma_{\mathrm{Y}}$ is finite can be determined:

$$
r_{p}=\frac{1}{4 \pi}\left(\frac{K_{1}}{\sigma_{Y}}\right)^{2}\left[\frac{3}{2} \sin ^{2} \theta+(1-2 v)^{2}(1+\cos \theta)\right]
$$

with the coordinate system origin at the crack tip.

Equation (A3) contains the stress intensity factor for the system being studied. Because of this it is difficult to make an a priori estimate of the plastic zone because of the SIF dependence on factors like specimen thickness and crack length. These results validate the assumption that the plastic zone is small. A plot of Eq. (A3) is shown in Fig. A1 with a yield stress $\sigma_{Y}=1$ bar, for ice of thickness $H=3000 \mathrm{~m}$ and crack depth $a=32 \mathrm{~m}$.

Differentiating Eq. (A3) with respect to $\theta$ gives the angle $\theta_{\max } \approx 1.512 \mathrm{rad}$, which maximizes the radial value defining the plastic zone for plane strain. When this value is combined with the maximum value of the stress intensity factor $\mathrm{K}_{1}$ found by differentiating and solving for the crevasse depth (see the convex profile of the stress intensity function in Fig. 9), the maximum extent of the plastic zone is shown to be 0.001 to 0.003 of ice thickness, for $H=3000 \mathrm{~m}$ and $H=1000 \mathrm{~m}$, respectively. 